\title{
FAKTOR-FAKTOR PEMANFAATAN PELAYANAN KESEHATAN DI PUSKESMAS PARUNG SELAMA MASA PANDEMI COVID-19 TAHUN 2021
}

\author{
Nena Mardiana ${ }^{1}$, Indira Chotimah ${ }^{2}$, Eny Dwimawati ${ }^{3}$ \\ 1 Peminatan Manajemen Pelayanan Kesehatan, Program Studi Kesehatan Masyarakat, Fakultas Ilmu \\ Kesehatan, Universitas Ibn Khaldun Bogor. Email : nenamardiana29@gmail.com \\ 2,3 Program Studi Kesehatan Masyarakat, Fakultas Ilmu Kesehatan, Universitas Ibn Khaldun Bogor. \\ Email :1indira.chotimah@gmail.com, ${ }^{2}$ enydwisutomo@gmail.com
}

\begin{abstract}
Abstrak
Penurunan kunjungan pasien pada Puskesmas Parung pada tahun 2020 disebutkan sebanyak 70,65\% masyarakat yang tidak memanfaatkan pelayanan kesehatatan. kapasitas puskesmas dalam memberikan layanan mengalami penurunan baik pada Upaya Kesehatan Masyarakat (UKM) dan upaya kesehatan perorangan (UKP). Metode yang digunakan merupakan metode penelitian kuantitatif dengan jumlah sampel sebanyak 130 responden menggunakan teknik accidental sampling. Instrumen yang digunakan dalam penelitian ini adalah kuesioner, data yang telah dikumpulkan selanjutnya diolah dan dianalisis dengan analisis data univariat, bivariat dan multivariat. Hasil penelitian menunjukkan bahwa sebanyak 130 responden diantaranya 27 responden $(20,8 \%)$ jarang memanfaatkan pelayanan kesehatan dan 103 responden $(79,2 \%)$ sering memanfaatkan pelayanan kesehatan. Berdasarkan uji bivariat dalam penelitian ini umur $(p=0,635)$, pendidikan $(p=0,047)$, pekerjaan $(p=0,454)$, aksesibilitas $(\mathrm{p}=0,006)$ dan pelayanan dokter $(\mathrm{p}=0,016)$, Ada hubungan terhadap pemanfaatan pelayanan kesehatan berdasarkan uji multivariat pada variabel pendidikan, aksesibilitas dan pelayanan dokter. Berdasarkan uji multivariat variabel aksesibilitas mempunyai nilai Exp (B) sebesar 0,269 dan variabel pelayanan dokter mempunyai nilai Exp (B) 0,282, merupakan model terbaik untuk menentukan determinan terhadap pemanfaatan pelayanan kesehatan di Puskesmas Parung.Peneliti dapat mengambil kesimpulan bahwa tingkat pendidikan,aksesbilitas dan pelayanan dokter memiliki hubungan yang signifikan terhadap pemanfaatan pelayanan kesehatan yang mana pelayanan dokter memiliki pengaruh yang besar. Saran dari peneliti kepada Puskesmas Parung agar terus meningkatkan dan mempertahankan pelayanan kesehatan yang tersedia serta lebih memperhatikan protokol kesehatan
\end{abstract}

Kata kunci : Pemanfaatan pelayanan kesehatan, aksesibilitas, pelayanan dokter, Covid19

\section{PENDAHULUAN}

Coronavirus Disease (2019) adalah penyakit menular yang disebabkan oleh Severe Acute Respirstitory Syndrome Coronavirus 2 (SARS-CoV-2). SARS-CoV-2 adalah jenis coronavirus baru yang belum pernah diidentifikasi sebelumnya oleh manusia. Terdapat 
dua jenis coronavirus yang diketahui dapat menyebabkan penyakit dengan menimbulkan gejala berat seperti Middle East Respiratory Syndrome (MERS) dan Severe Acute Respiratory Syndrome (SARS). (Kemenkes RI, 2020).

Kementerian Kesehatan Republik Indonesia menyatakan Kasus Covid-19 di dunia sampai saat ini tanggal 30 Oktober 2020 mencapai 44.351 .506 kasus positif, jumlah kasus meninggal sebanyak 1.171.255 jiwa, hal ini sangat berisiko global yang sangat tinggi. Kasus Covid-19 di Indonesia dilaporkan pertama kali pada tanggal 2 Maret 2020 dan hingga saat ini terdapat 404.048 kasus positif Covid-19, jumlah pasien sembuh dari Covid-19 sebanyak 330.000 orang dan total angka kematian pasien Covid-19 di Indonesia sebanyak 13.701 orang. Jumlah pasien yang terkonfirmasi di Jawa Barat pada tanggal 30 oktober 2020 sebanyak 35.607 kasus yang dinyatakan positif Covid-19, kemudian total pasien sembuh sebanyak 24.999 orang dan total pasien Covid-19 yang meninggal dunia sebanyak 714 orang. Bogor Pada tanggal 28 oktober 2020 terkonfirmasi positif Covid-19 mencapai 2.646 orang, sedangkan kasus yang sembuh sebanyak 2.161 orang dan jumlah meninggal akibat Covid-19 sebanyak 62 orang (Peta Sebaran Covid-19 Kabupaten Bogor, 2020).

Pemanfaatan pelayanan kesehatan adalah penggunaan fasilitas pelayanan kesehatan yang disediakan baik oleh pemerintah maupun swasta dalam bentuk rawat jalan, rawat inap, kunjungan rumah oleh tenaga kesehatan ataupun bentuk kegiatankegiatan lain dari pemanfaatan pelayanan kesehatan tersebut (Mubarak dan Cahyati, 2009). Penduduk yang berkunjung ke Puskesmas Parung untuk memanfaatkan pelayanan kesehatan rawat jalan maupun rawat inap pada bulan april sampai desember 2019 sebanyak 32.895 pasien, kemudian ditahun 2020 bulan januari sampai maret sebelum adanya Covid-19 jumlah pasien yang berkunjung sebanyak 11.614 pasien, sedangkan pada bulan April sampai Oktober 2020 pasien yang berkunjung untuk memanfaatkan pelayanan kesehatan mengalami jumlah penurunan dari bulan sebelumnya. Jumlah pasien yang berkunjung untuk memanfaatkan pelayanan kesehatan pada saat masa pandemi Covid-19 sebanyak 13.063 pasien. Kepala Tata Usaha Puskesmas Parung menyatakan bahwa pada Masa pandemi Covid-19 dapat mempengaruhi kunjungan pasien terhadap pemanfaatan pelayanan kesehatan di Puskesmas Parung. Penurunan kunjungan pasien pada masa pandemi Covid-19 saat ini sebanyak 70,65\% masyarakat yang tidak memanfaatkan pelayanan kesehatan di Puskesmas Parung.

Umur adalah jumlah tahun yang telah dilalui oleh seseorang dari awal dilahirkan sampai ulang tahun terakhir. Menurut Notoatmodjo (2005) umur merupakan salah satu faktor yanag dapat mempengaruhi pemanfaatan pelayanan kesehatan, kelompok usia muda ternyata lebih rentan terhadap penyakit seperti diare, infksi saluran pernafasan, dan lain-lain. Sedangkan untuk usia produktif lebih cenderung dengan berhadapan dengan masalah keselakaan lalu lintas, kecelakaan kerja, dan penyakit akibat gaya hidup yang kurag sehat, dan untuk usia yang relatif lebih tua atau lansia sangat rentan dengan penyakit kronis seperti hipertensi, jantung koroner dan kanker.

Menurut L. Green Secara teoritis pendidikan formal akan sangat mempengaruhi pengetahuan seseorang, sehingga apabila seseorang mempunyai pendidikan formal 
yang tinggi akan mempunyai pengetahuan yang lebih tinggi dan lebih luas wawasannya dibandingkan dengan seseorang yang berpendidikan rendah. Pendidikan seseorang yang lebih tinggi diharapkan lebih cepat dan lebih mudah memahami pentingnya penyakit dan pemanfaatan pelayanan kesehatan (Notoatmodjo, 1993).

Pekerjaan dapat berkaitan dengan kesehatan seseorang, dimana timbulnya penyakit dapat melalui beberapa cara yaitu dengan adanya faktor-faktor lingkungan yang langsung dapat menimbulkan kesakitan, situasi pekerjaan yang penuh dengan stress dan kurangnya aktifitas didalam pekerjaan atau saat bekerja.

Akses adalah kesempatan untuk mengidentifikasi kebutuhan kesehatan, untuk mencari layanan kesehatan, mencapai, mendapatkan sumber daya, menggunakan layanan kesehatan, dan untuk benar-benar memiliki kebutuhan untuk layanan kesehatan yang tepat agar bisa terpenuhi (Levesque At Al., 2013).

Pelayanan kedokteran (medical srvice) bertujuan untuk mengobati penyakit ataupun memulihkan kesehatan dimana sasaran ini ditujukan kepada setiap individu dan keluarga, pelayanan kedokteran dapat dilakukan secara mandiri maupun secara bersama-sama dalam suatu organisasi.

\section{METODE}

Penelitian ini menggunakan pendekatan kuantitatif observasional dengan desain Cross Sectional (potong lintang) dengan metode pengisian kuesioner untuk mengetahui hubungan antara variabel dependen pemanfaatan pelayanan kesehatan dan variabel independen umur, pendidikan, pekerjaan, aksesibilitas, dan pelayanan dokter yang diambil dalam waktu bersamaan. Waktu penelitian dilaksanakan pada 4 September 2021 sampai 10 september 2021. Populasi penelitian ini adalah seluruh orang dewasa dalam keluarga atau dalam rumah tangga yang bertempat tinggal di wilayah kerja Puskesmas Parung, Jumlah populasi yang bertempat tinggal di wilayah kerja Puskesmas Parung sebanyak 99.163 orang. Pengambilan sampel pada penelitian ini dilakukan dengan menggunakan non probability sampling berupa accidental sampling, yaitu mengambil sampel dengan yang kebetulan tersedia disuatu tempat. Responden yang diambil untuk sampel sebanyak 130 responden. Analisis univariat yaitu untuk mengetahui gambaran distribusi frekuensi dari variabel karakteristik, independen dan dependen yang diteliti. Analisis bivariat (chi-square) untuk menganalisis hubungan antara variabel independen dengan dependen yaitu umur, pendidikan, pekerjaan, aksesibilitas dan pelayanan dokter. Sedangkan analisis multivariat adalah untuk melihat seberapa besar pengaruh antara 2 variabel atau lebih. 
HASIL

Analisis Univariat

Tabel 1 Distribusi Frekuensi Berdasarkan Umur Pasien Yang Memanfaatkan Pelayanan Kesehatan Di Puseksmas Parung

\begin{tabular}{ccc}
\hline Umur & $\begin{array}{c}\text { Frekuensi } \\
\mathrm{n}\end{array}$ & $\begin{array}{c}\text { Persentase } \\
\%\end{array}$ \\
\hline 17-55 Tahun & 123 & 94,6 \\
\hline$>$ 55 Tahun & 7 & 5,4 \\
\hline Total & 130 & 100,0 \\
\hline Sumber: Data Primer 2021 &
\end{tabular}

Berdasarkan hasil frekuensi pada tabel 1diketahui bahwa dari 130 responden terdapat 123 responden $(94,6 \%)$ pada kriteria umur 17-55 tahun dan 7 responden $(5,4 \%)$ pada kriteria umur $>55$ tahun yang memanfaatkan pelayanan kesehatan di Puskesmas Parung selama masa pandemi Covid-19.

Tabel 2 Distribusi Frekuensi Berdasarkan Jenis Kelamin Pasien Yang Memanfaatkan Pelayanan Kesehatan Di Puseksmas Parung

\begin{tabular}{ccc} 
Jenis Kelamin & $\begin{array}{c}\text { Frekuensi } \\
\mathrm{n}\end{array}$ & $\begin{array}{c}\text { Persentase } \\
\%\end{array}$ \\
\hline Laki-laki & 47 & 36,2 \\
\hline Perempuan & 83 & 63,8 \\
\hline Total & 130 & 100,0 \\
\hline
\end{tabular}

Sumber: Data Primer 2021

Berdasarkan hasil frekuensi pada tabel 2 diketahui bahwa dari 130 responden terdapat 47 responden (36,2\%) berjenis kelamin laki-laki dan 83 responden $(63,8 \%)$ berjenis kelamin perempuan yang memanfaatkan pelayanan kesehatan di Puskesmas Parung selama masa pandemi Covid-19.

Tabel 3 Distribusi Frekuensi Berdasarkan Tingkat Pendidikan Pasien Yang Memanfaatkan Pelayanan Kesehatan Di Puseksmas Parung

\begin{tabular}{ccc}
\hline Pendidikan & $\begin{array}{c}\text { Frekuensi } \\
\mathrm{n}\end{array}$ & $\begin{array}{c}\text { Persentase } \\
\%\end{array}$ \\
\hline Tidak sekolah & 3 & 2,3 \\
\hline SD & 9 & 6,9 \\
\hline SMP & 14 & 10,8 \\
\hline SMA & 76 & 58,5 \\
\hline Perguruan Tinggi & 28 & 21,5 \\
\hline Total & 130 & 100,0 \\
\hline Sumber: Data Primer 2021 &
\end{tabular}


Berdasarkan hasil frekuensi diketahui bahwa dari 130 responden terdapat 26 responden $(18,5 \%)$ berpendidikan rendah yaitu 3 responden $(2,3 \%)$ tidak bersekolah, 9 responden $(6,9 \%)$ berpendidikan SD dan 14 responden $(10,8 \%)$ berpendidikan SMP sedangkan, 104 responden $(81,5 \%)$ yang memiliki kriteria pendidikan tinggi diantaranya yaitu 76 responden (58,5\%) berpendidikan SMA dan 28 responden $(21,5 \%)$ berpendidikan sampai menempuh perguruan tinggi.

Tabel 4 Distribusi Frekuensi Berdasarkan Jenis Pekerjaan Pasien Yang Memanfaatkan Pelayanan Kesehatan Di Puseksmas Parung

\begin{tabular}{ccc}
\hline Pekerjaan & $\begin{array}{c}\text { Frekuensi } \\
\mathrm{n}\end{array}$ & $\begin{array}{c}\text { Persentase } \\
\%\end{array}$ \\
\hline Tidak Bekerja & 49 & 37,7 \\
Buruh & 37 & 28,5 \\
Swasta & 41 & 31,5 \\
PNS & 3 & 2,3 \\
\hline Total & 130 & 100,0 \\
\hline
\end{tabular}

Sumber: Data Primer 2021

Berdasarkan hasil frekuensi diketahui bahwa dari 130 responden terdapat 49 responden $(37,7 \%)$ berada pada kriteria tidak bekerja dan 81 responden $(62,3 \%)$ berada pada kriteria bekerja yang diantaranya yaitu 37 responden (28,5\%) bekerja sebagai buruh, 41 responden (31,5\%) pekerja swasta dan 3 responden (2,3\%) PNS yang memanfaatkan pelayanan kesehatan di Puskesmas Parung selama masa pandemi Covid19.

Tabel 5 Distribusi Frekuensi Berdasarkan Aksesibilitas (Jarak, Transportasi, Waktu Tempuh) Pasien Yang Memanfaatkan Pelayanan Kesehatan Di Puseksmas Parung

\begin{tabular}{ccc}
\hline Aksesibilitas & $\begin{array}{c}\text { Frekuensi } \\
\mathrm{n}\end{array}$ & $\begin{array}{c}\text { Persentase } \\
\%\end{array}$ \\
\hline Sulit & 26 & 20,0 \\
\hline Mudah & 104 & 80,0 \\
\hline Total & 130 & 100,0 \\
\hline Sumber: Data Primer 2021 &
\end{tabular}

Berdasarkan hasil frekuensi pada tabel 5 diketahui bahwa dari 130 responden terdapat 26 responden (20,0\%) berada pada kriteria aksesibilitas yang sulit dan 104 responden $(80,0 \%)$ berada pada kriteria aksesibilitas yang mudah untuk memanfaatkan pelayanan kesehatan di Puskesmas Parung selama masa pandemi Covid-19. 
Tabel 6 Distribusi Frekuensi Berdasarkan Pelayanan Dokter pada Pasien Yang Memanfaatkan Pelayanan Kesehatan Di Puseksmas Parung

\begin{tabular}{ccc}
$\begin{array}{c}\text { Pelayanan } \\
\text { Dokter }\end{array}$ & $\begin{array}{c}\text { Frekuensi } \\
\mathbf{n}\end{array}$ & $\begin{array}{c}\text { Persentase } \\
\text { \% }\end{array}$ \\
\hline Kurang Baik & 15 & 11,5 \\
\hline Baik & 115 & 88,5 \\
\hline Total & 130 & 100,0 \\
\hline
\end{tabular}

Sumber: Data Primer 2021

Berdasarkan hasil frekuensi pada tabel 6 diketahui bahwa dari 130 responden terdapat 15 responden $(11,5 \%)$ berada pada kriteria pelayanan dokter yang kurang baik dan 115 responden (88,5\%) berada pada kriteria pelayanan dokter yang baik dalam memanfaatkan pelayanan kesehatan di Puskesmas Parung selama masa pandemi Covid-19.

Tabel 7 Distribusi Frekuensi Pemanfaatan Pelayanan Kesehatan pada Pasien Yang Memanfaatkan Pelayanan Kesehatan Di Puseksmas Parung

\begin{tabular}{ccc}
\hline $\begin{array}{c}\text { Pemanfaatan } \\
\text { Pelayanan } \\
\text { Kesehatan }\end{array}$ & $\begin{array}{c}\text { Frekuensi } \\
\mathbf{n}\end{array}$ & $\begin{array}{c}\text { Persentase } \\
\mathbf{\%}\end{array}$ \\
\hline Jarang & 27 & 20,8 \\
\hline Sering & 103 & 79,2 \\
\hline Total & 130 & 100,0 \\
\hline
\end{tabular}

Sumber: Data Primer 2021

Berdasarkan hasil frekuensi pada tabel 7 diketahui bahwa dari 130 responden terdapat 27 responden $(20,8 \%)$ jarang memanfaatkan pelayanan kesehatan dan 103 responden $(79,2 \%)$ sering memanfaatkan pelayanan kesehatan di Puskesmas Parung selama masa pandemiCovid-19.

\section{Analisis Bivariat}

Tabel 8 Analisis chi square berdasarkan hubungan antara Umur dengan Pemanfaatan Pelayanan Kesehatan Di Puseksmas Parung

\begin{tabular}{|c|c|c|c|c|c|c|c|c|}
\hline \multirow{3}{*}{$\begin{array}{l}\text { Umur } \\
\text { (Tahun) }\end{array}$} & \multicolumn{4}{|c|}{ Pemanfaatan Pelayanan Kesehatan } & \multirow{2}{*}{\multicolumn{2}{|c|}{ Total }} & \multirow{3}{*}{ P.Value } & \multirow{3}{*}{ OR } \\
\hline & \multicolumn{2}{|c|}{ Jarang } & \multicolumn{2}{|c|}{ Sering } & & & & \\
\hline & $\mathrm{N}$ & $\%$ & $\mathrm{~N}$ & $\%$ & $\mathrm{~N}$ & $\%$ & & \\
\hline $17-55$ & 25 & 20,3 & 98 & 79,7 & 123 & 100,0 & & \\
\hline$>55$ & 2 & 28,6 & 5 & 71,4 & 7 & 100,0 & 0.538 & $\begin{array}{c}0,638(0,117 \\
3,483)\end{array}$ \\
\hline Total & 27 & 20,8 & 103 & 79,2 & 130 & 100,0 & & \\
\hline
\end{tabular}

Sumber: Data Primer 2021 
Berdasarkan tabel 8 didapatkan bahwa dari 123 responden berusia 17-15 tahun, sebanyak 25 responden $(20,5 \%)$ jarang memanfaatkan pelayanan kesehatan dan 98 responden $(79,7 \%)$ sering memanfaatkan pelayanan kesehatan. sedangkan dari 7 responden berusia > 55 tahun, sebanyak 2 respoden $(20,5 \%)$ jarang memanfaatkan pelayanan kesehatan dan 5 responden $(71,4 \%)$ sering memanfaatkan pelayanan kesehatan selama masa covid-19.

Dari hasil uji statistik yang dilakukan menggunakan chi-square mendapatkan nilai $p$-value $=0,635$ dimana nilai $p$-value $>0,05$. Maka dapat disimpulkan bahwa tidak ada hubungan yang signifikan antara umur responden dengan pemanfaatan pelayanan kesehatan di wilayah kerja Puskesmas Parung selama masa pandemi Covid-19.

Tabel 9 Analisis chi square berdasarkan hubungan antara Pendidikan dengan Pemanfaatan Pelayanan Kesehatan Di Puseksmas Parung

\begin{tabular}{|c|c|c|c|c|c|c|c|c|}
\hline \multirow{3}{*}{ Pendidikan } & \multicolumn{4}{|c|}{ Pemanfaatan Pelayanan Kesehatan } & \multirow{2}{*}{\multicolumn{2}{|c|}{ Total }} & \multirow{3}{*}{ P.Value } & \multirow{3}{*}{ OR } \\
\hline & \multicolumn{2}{|l|}{ Jarang } & \multicolumn{2}{|c|}{ Sering } & & & & \\
\hline & $\mathrm{n}$ & $\%$ & $\mathrm{~N}$ & $\%$ & $\mathrm{~N}$ & $\%$ & & \\
\hline Rendah & 9 & 37,5 & 15 & 62,5 & 24 & 100,0 & & \\
\hline Tinggi & 18 & 17,0 & 88 & 83,0 & 106 & 100,0 & 0.047 & $\begin{array}{c}2,933 \\
(1,112-\end{array}$ \\
\hline Total & 27 & 20,8 & 103 & 79,2 & 130 & 100,0 & & $7,734)$ \\
\hline
\end{tabular}

Sumber: Data Primer 2021

Berdasarkan tabel 9 didapatkan bahwa dari 24 responden berpendidikan rendah, sebanyak 9 responden 37,5\%) jarang memanfaatkan pelayanan kesehatan dan 15 responden (62,5\%) sering memanfaatkan pelayanan kesehatan. Sedangkan dari 106 responden berpendidikan tinggi, sebanyak 18 respoden $(17,0 \%)$ jarang memanfaatkan pelayanan kesehatan dan 88 responden $(83,0 \%)$ sering memanfaatkan pelayanan kesehatan selama masa covid-19.

Dari hasil uji statistik yang dilakukan menggunakan chi-square mendapatkan nilai $p$-value $=0,047$ dimana nilai $p$-value $>0,05$. Maka dapat disimpulkan bahwa ada hubungan yang signifikan antara pendidikan responden dengan pemanfaatan pelayanan kesehatan di wilayah kerja Puskesmas Parung selama masa pandemi Covid19. 
Tabel 10 Analisis chi square berdasarkan hubungan antara Pekerjaan dengan Pemanfaatan Pelayanan Kesehatan Di Puseksmas Parung

\begin{tabular}{|c|c|c|c|c|c|c|c|c|}
\hline \multirow{3}{*}{ Pekerjaan } & \multicolumn{4}{|c|}{ Pemanfaatan Pelayanan Kesehatan } & \multirow{2}{*}{\multicolumn{2}{|c|}{ Total }} & \multirow{3}{*}{ P-Value } & \multirow{3}{*}{ OR } \\
\hline & \multicolumn{2}{|c|}{ Jarang } & \multicolumn{2}{|c|}{ Sering } & & & & \\
\hline & $\mathrm{N}$ & $\%$ & $\mathrm{n}$ & $\%$ & $\mathrm{~N}$ & $\%$ & & \\
\hline Tidak Bekerja & 8 & 16,3 & 41 & 83,7 & 49 & 100,0 & & \\
\hline Bekerja & 19 & 23,5 & 62 & 76,5 & 81 & 100,0 & 0.454 & $\begin{array}{c}0,637 \\
(0,255-\end{array}$ \\
\hline Total & 27 & 20,8 & 103 & 79,2 & 130 & 100,0 & & \\
\hline
\end{tabular}

Sumber: Data Primer 2021

Berdasarkan tabel 10 didapatkan bahwa dari 49 responden yang tidak bekerja, sebanyak 8 responden (16,3\%) jarang memanfaatkan pelayanan kesehatan dan 41 responden $(83,7 \%)$ sering memanfaatkan pelayanan kesehatan. Sedangkan dari 81 responden yang bekerja, sebanyak 19 respoden (23,5\%) jarang memanfaatkan pelayanan kesehatan dan 62 responden (76,5\%) sering memanfaatkan pelayanan kesehatan selama masa covid-19

Dari hasil uji statistik yang dilakukan menggunakan chi-square mendapatkan nilai $p$-value $=0,454$ dimana nilai $p$-value $>0,05$. Maka dapat disimpulkan bahwa tidak ada hubungan yang signifikan antara pekerjaan responden dengan pemanfaatan pelayanan kesehatan di wilayah kerja Puskesmas Parung selama masa pandemi Covid-19.

Tabel 11 Analisis chi square berdasarkan hubungan antara Aksesibilitas (Jarak, Transportasi dan Waktu Tempuh) dengan Pemanfaatan Pelayanan Kesehatan Di Puseksmas Parung

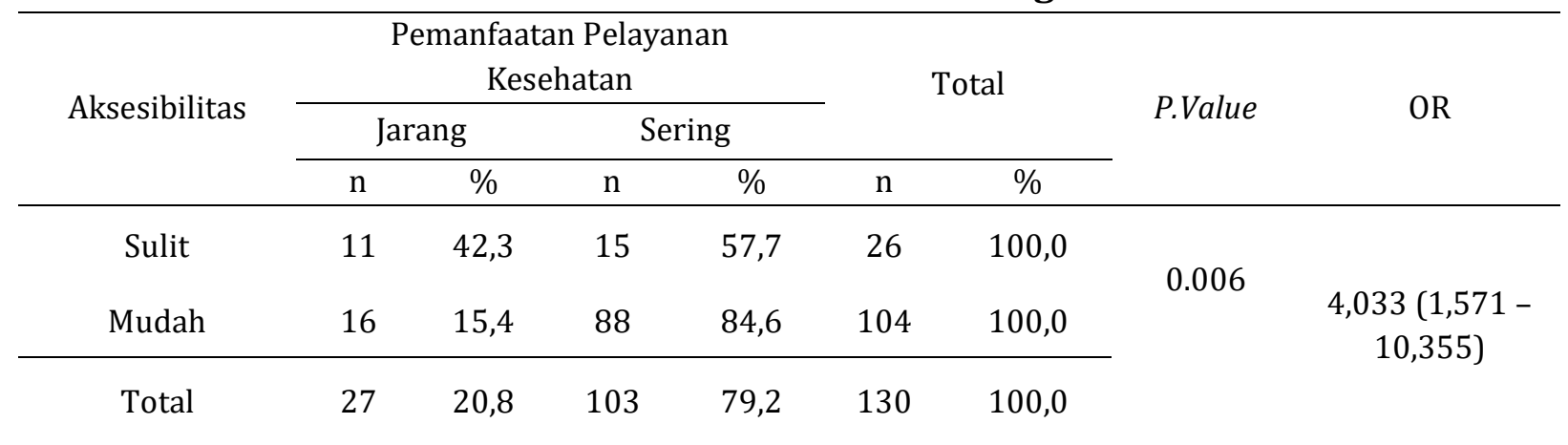

Sumber: Data Primer 2021

Berdasarkan tabel 11 didapatkan bahwa dari 26 responden yang mengalami kesulitan dalam mengakses pelayaanan kesehatan, sebanyak 11 responden (42,3\%) jarang memanfaatkan pelayanan kesehatan dan 15 responden (57,7\%) sering memanfaatkan pelayanan kesehatan. Sedangkan dari 104 responden yang yang mudah dalam mengakses pelayaanan kesehatan sebanyak 16 respoden $(15,4 \%)$ jarang 
memanfaatkan pelayanan kesehatan dan 88 responden $(84,6 \%)$ sering memanfaatkan pelayanan kesehatan selama masa covid-19

Dari hasil uji statistik yang dilakukan menggunakan chi-square mendapatkan nilai $p$-value $=0,006$ dimana nilai $p$-value $>0,05$. Maka dapat disimpulkan bahwa ada hubungan yang signifikan antara aksesibilitas responden dengan pemanfaatan pelayanan kesehatan di wilayah kerja Puskesmas Parung selama masa pandemi Covid19.

Tabel 12 Analisis chi square berdasarkan hubungan antara Pelayanan Dokter dengan Pemanfaatan Pelayanan Kesehatan Di Puseksmas Parung

\begin{tabular}{|c|c|c|c|c|c|c|c|c|}
\hline \multirow{3}{*}{ Pelayanan Dokter } & \multicolumn{4}{|c|}{$\begin{array}{c}\text { Pemanfaatan Pelayanan } \\
\text { Kesehatan }\end{array}$} & \multirow{2}{*}{\multicolumn{2}{|c|}{ Total }} & \multirow{3}{*}{ P.Value } & \multirow{3}{*}{$\mathrm{OR}$} \\
\hline & \multicolumn{2}{|c|}{ Jarang } & \multicolumn{2}{|c|}{ Sering } & & & & \\
\hline & $\mathrm{N}$ & $\%$ & $\mathrm{n}$ & $\%$ & $\mathrm{n}$ & $\%$ & & \\
\hline Kurang Baik & 7 & 46,7 & 8 & 53,3 & 15 & 100,0 & & \\
\hline Baik & 20 & 17,4 & 95 & 82,6 & 115 & 100,0 & 0.016 & $\begin{array}{c}4,156 \\
(1,352-\end{array}$ \\
\hline Total & 27 & 20,8 & 103 & 79,2 & 130 & 100,0 & & \\
\hline
\end{tabular}

Sumber: Data Primer 2021

Berdasarkan tabel 12 didapatkan bahwa dari 15 responden merasa kurang baik dalama pelayanan kesehatan, sebanyak 7 responden $(46,7 \%)$ jarang memanfaatkan pelayanan kesehatan dan 8 responden (53,3\%) sering memanfaatkan pelayanan kesehatan. Sedangkan dari 115 responden yang merasa baik dalama pelayanan kesehatan sebanyak 20 respoden $(17,4 \%)$ jarang memanfaatkan pelayanan kesehatan dan 95 responden $(82,6 \%)$ sering memanfaatkan pelayanan kesehatan selama masa covid-19.

Dari hasil uji statistik yang dilakukan menggunakan chi-square mendapatkan nilai $p$-value $=0,016$ dimana nilai $p$-value $>0,05$. Maka dapat disimpulkan bahwa ada hubungan yang signifikan antara pelayanan dokter dengan pemanfaatan pelayanan kesehatan di wilayah kerja Puskesmas Parung selama masa pandemi Covid-19.

\section{Analisis Multivariat}

Tabel 13 Hasil Uji Regresi Logistik Berganda

\begin{tabular}{lcc}
\hline \multicolumn{1}{c}{ Variabel } & $P($ value $)$ & EXP (B) \\
\hline Aksesibilitas & 0,002 & 0,269 \\
\hline Pelayanan Dokter & 0,010 & 0,282 \\
\hline Sumber: Data Primer 2021 & &
\end{tabular}

Berdasarkan tabel 13 didapatkan bahwa variabel aksesibilitas $(p=0,002)$ dan mempunyai nilai Exp (B) 0,269, artinya responden yang aksesibilitasnya mudah akan memanfaatkan pelayanan kesehatan sebanyak 0,269 kali lebih besar dibandingkan dengan 
responden yang aksesibilitasnya sulit. Variabel pelayanan dokter $(p=0,010)$ dan mendapatkan nilai Exp (B) 0,282, artinya responden yang merasa pelayanan dokter dengan baik akan memanfaatkan pelayanan kesehatan sebanyak 0,282 kali lebih besar dibandingkan dengan responden yang merasa kurang baik dalam pelayanan dokter.

\section{PEMBAHASAN}

\section{a. Hubungan Umur dengan Pemanfaatan Pelayanan Kesehatan Di Puseksmas Parung Selama Masa Pandemi Covid-19}

Hasil penelitian yang dilakukan kepada 130 responden dapat dilihat bahwa tidak ada hubungan yang signifikan antara umur responden dengan pemanfaatan pelayanan kesehatan di wilayah kerja Puskesmas Parung selama masa pandemi Covid-19 dengan hasil uji statistik yang dilakukan menggunakan chi-square mendapatkan nilai $p$-value $=0,635$ dimana nilai $p$-value $>0,05$.

Hasil penelitian ini sejalan dengan wahyuni (2012) bahwa tidak ada perbedaan pemanfaatan pelayanan kesehatan antara responden dengan umur muda (17-55 tahun) dan umur tua atau lansia ( $>55$ tahun). Responden kriteria umur $>55$ tahun lebih rendah untuk tidak memanfaatkan pelayanan kesehatan dibanding dengan responden dengan kritria umur 17-55 tahun, dengan nilai $p$-value $=0,459$ yang berarti tidak ada hubungan signifikan diantaranya.

Hasil penelitian yang didapat pada responden kriteria umur 17-55 tahun di Puskesmas Parung lebih sering dalam memanfaatkan pelayanan kesehatan selama masa pandemi Covid-19. Hal ini bisa terjadi karena pada usia 17-55 tahun masih banyak masyarakat yang belum menerapkan hidup bersih dan sehat, sehingga dapat menyebabkan penyakit yang sering dialami oleh masyarakat lain, misalnya seperti makan makanan yang tidak sehat dapat mengakibatkan diare bahkan apabila terlalu sering memakan makanan yang tidak sehat dapat mengakibatkan penyakit yang lebih serius. Masalah kecelakaan lalu lintas pula masih sering dijumpai karena masa usia produktif banyak yang berkendara dengan kurang berhati-hati terlebih orang yang ingin berangkat kerja yang berada dalam kondisi terburu-buru. Maka dari itu hasil penelitian yang menunjukkan bahwa usia 17-55 tahun yang lebih sering memanfaatkan pelayanan kesehatan lebih rentan terserang penyakit.

Peneliti menggunakan kategori umur menurut Depkes RI tahun 2009 dimana kategori umur dapat di bedakan dari balita sampai manula, namun dalam proses pembuatan kuesioner dan pengolahan data peneliti hanya menjadikan 2 kategori, yaitu kategori umur 17-55 tahun dan kategori umur > 55 tahun karena pada saat proses pengolahan data menggunakan uji statistik Chi-square hanya menggunakan tabel 2 X 2. Tujuan uji Chi-square adalah untuk menguji perbedaan persentase antara dua atau lebih kelompok (sampel). Tabel $2 \times 2$ yang dimaksud adalah variabel independen dan variabel dependen masing-masing terdiri dari 2 kelompok atau lebih. Pada kategori umur 17-55 tahun terdapat beberapa kategori umur diantaranya yaitu, umur 17-25 tahun termasuk dalam kategori masa remaja akhir, umur 26-35 tahun merupakan kategori dewasa awal, umur 36-45 tahun adalah 
kategori masa dewasa akhir, umur 46-55 tahun yaitu kategori lansia awal dan pada kategori umur > 55 tahun apat dikategorikan lansia akhir sampai dengan manula.

\section{b. Hubungan Pendidikan dengan Pemanfaatan Pelayanan Kesehatan Di Puseksmas Parung Selama Masa Pandemi Covid-19}

Hasil penelitian yang dilakukan kepada 130 responden dapat dilihat bahwa ada hubungan yang signifikan antara pendidikan responden dengan pemanfaatan pelayanan kesehatan di wilayah kerja Puskesmas Parung selama masa pandemi Covid-19 dengan hasil uji statistik yang dilakukan menggunakan chi-square mendapatkan nilai $p$-value $=0,047$ dimana nilai $p$-value $>0,05$.

Hasil penelitian ini sejalan dengan Azura (2016) bahwa ada hubungan yang signifikan terhadap pendidikan dengan pemanfaatan puskesmas oleh peserta jaminan kesehatan (JKN) dengan hasil analisis uji multivariate menggunakan uji regresi logistik berganda $p$-value $=0,007(p<0,05)$ dan nilai $\operatorname{Exp}(B) 0,106$. Responden yang berpendidikan tinggi akan memanfaatkan puskesmas 0,106 kali lebih besar dibandingkan dengan responden yang berpendidikan rendah.

Berdasarkan hasil penelitian yang dilakukan di Puskesmas Parung didapatkan hasil bahwa responden yang memanfaatkan pelayanan kesehatan lebih banyak yang berpendidikan tinggi dan lebih dominan pada pendidikan SMA. Responden dengan pendidikan tinggi akan lebih mementingkan kesehatannya, karena jika sudah melakukan pengobatan secara mandiri dirumah namun tidak kunjung membaik dalam beberapa hari maka responden akan mengkonsultasikan keluhannya kepada dokter agar mendapatkan penanganan yang lebih baik dan maksimal agar kondisi tubuhnya kembali seperti biasanya dalam keadaan sehat. Berebeda dengan responden yang berpendidikan rendah, jika merasa dirinya sakit akan melakukan pengobatan secara mandiri, biasanya dengan meminum ramuan herbal yang dibuat sendiri. Responden yang berpendidikan rendah akan memanfaatkan pelayanan kesehatan apabila ia sudah tidak mampu lagi untuk beraktivitas dalam kesehariannya, karena mereka menganggap bahwa sakit yang mereka rasakan hanyalah sebagai rasa kelelahan, masuk angin, dan diare pada umumnya sering dialami.

\section{c. Hubungan Pekerjaan dengan Pemanfaatan Pelayanan Kesehatan Di Puseksmas Parung Selama Masa Pandemi Covid-19}

Hasil penelitian yang dilakukan kepada 130 responden dapat dilihat bahwa tidak ada hubungan yang signifikan antara pekerjaan responden dengan pemanfaatan pelayanan kesehatan di wilayah kerja Puskesmas Parung selama masa pandemi Covid-19 dengan hasil uji statistik yang dilakukan menggunakan chi-square mendapatkan nilai $p$-value $=0,454$ dimana nilai $p$-value $>0,05$.

Penelitian ini sejalan oleh Azura (2016) bahwa tidak ada hubungan yang signifikan antara pekerjaan dengan pemanfaatan pelayanan kesehatan di puskesmas, dengan hasil analisis uji chi-square dengan mendapatkan nilai $p$-value $=0,319$ dimana nilai ( $p$-value $=>0,05$ ). 
Semakin tinggi jabatan pekerjaan responden maka akan semakin jarang untuk memanfaatkan pelayanan kesehatan ke Puskesmas, hal ini berhubungan dengan pendapatan responden karena apabila responden bekerja pada perusahaan maka akan mendapatkan jaminan kesehatan untuk mendapatkan pelayanan kesehatan yang lebih baik dari pada pelayanan kesehatan di Puskesmas dan akan mendapatkan kualitas obat yang didapatkan akan lebih baik dibandingkan dengan obat yang diberikan oleh pelayanan kesehatan di Puskesmas. Begitupun sebaliknya apabila responden bekerja hanya sebagai buruh maka pendapatannyapun lebih sedikit atau lebih kecil dari responden yang bekerja di perusahaan besar, maka responden yang bekerja sebagai buruh akan lebih sering memanfaatkan pelayanan kesehatan di Puskesmas Parung.

\section{d. Hubungan Aksesibilitas (Jarak, Transportasi dan Waktu Tempuh) dengan Pemanfaatan Pelayanan Kesehatan Di Puseksmas Parung Selama Masa Pandemi Covid-19}

Hasil regresi logistik mendapatkan nilai $p$-value $=0,002$ dimana nilai $p$-value $>$ 0,05 yang berarti ada pengaruh antara variabel aksesibilitas (jarak, transportasi dan waktu tempuh) dengan pemanfaatan pelayanan kesehatan di Puskesmas Parung. Mempunyai nilai Exp (B) 0,269, artinya responden yang aksesibilitasnya mudah akan memanfaatkan pelayanan kesehatan sebanyak 0,269 kali lebih besar dibandingkan dengan responden yang aksesibilitasnya sulit.

Penelitian ini sejalan dengan Tampubolon (2018) bahwa hasil uji regresi logistik mendapatkan hasil $\mathrm{p}=0,031(\mathrm{p}<0,05)$ yang berarti ada hubungan yang signifikan antara variabel aksesibilitas (jarak tempuh, biaya, dan transportasi) dengan pemanfaatan pelayanan kesehatan di Puskesmas Parlilitan.

Hasil penelitian yang telah dilakukan menyatakan bahwa aksesibilitas (jarak, transportasi dan waktu tempuh) untuk memanfaatkan pelayanan kesehatan ke Puseksmas Parung mudah, karena lokasi Puskesmas yang sangat strategis yaitu tepat dipinggir jalan raya, sehingga pasien tidak kesulitan untuk memanfaatkan pelayanan kesehatan. Transportasi untuk menuju Puskesmas Parung pun sangat mudah karena apabila responden tidak menggunakan transportasi pribadi miliknya mereka tetap dapat memanfaatkan pelayanan kesehatan dengan menggunakan transportasi umum.

\section{e. Hubungan Pelayanan Dokter dengan Pemanfaatan Pelayanan Kesehatan Di Puseksmas Parung Selama Masa Pandemi Covid-19}

Hasil regresi logistik mendapatkan nilai $p$-value $=0,010$ dimana nilai $p$-value $>$ 0,05 yang berarti ada pengaruh antara variabel tenaga dokter dengan pemanfaatan pelayanan kesehatan di Puskesmas Parung. Mempunyai nilai Exp (B) 0,282 artinya responden yang merasa pelayanan dokter dengan baik akan memanfaatkan pelayanan kesehatan sebanyak 0,282 kali lebih besar dibandingkan dengan responden yang merasa kurang baik dalam pelayanan dokter.

Penelitian ini sejalan dengan Manalu (2018) menyatakan bahwa hasil uji chisquare menunjukkan ada hubungan yang signifikan antara pelayanan dokter dengan 
pemanfaatan pelayanan kesehatan di Puskesmas dengan nilai $\mathrm{p}<0,001(\mathrm{p}<0,05)$. Hal ini menunjukkan bahwa akan terjadi peningkatan pemanfaatan pelayanan kesehatan di Puskesmas apabila peran pelyanan dokter meningkat.

Dari hasil penelitian yang telah dilakukan oleh peneliti, pelayanan dokter sangat berpengaruh untuk pasien yang memanfaatkan pelayanan kesehatan di Puskesmas Parung. Hal ini dapat dilihat dari baik atau kurang baik pelayanan dokter terhadap pasien pada saat memeriksakan kesehatan, apabila pelayanan dokter baik maka akan mempengaruhi penilaian responden dengan sering memanfaatkan pelayanan kesehatan ke Puskesmas Parung saat kondisi tubuhnya sedang tidak baik-baik saja dan responden akan merasa puas apabila yang mereka butuhkan dipenuhi oleh Puskesmas.

\section{KESIMPULAN}

Peneliti dapat mengambil kesimpulan bahwa tingkat pendidikan,aksesbilitas dan pelayanan dokter memiliki hubungan yang signifikan terhadap pemanfaatan pelayanan kesehatan yang mana pelayanan dokter memiliki pengaruh yang besar.

\section{SARAN}

Saran dari peneliti kepada Puskesmas Parung agar terus meningkatkan dan mempertahankan pelayanan kesehatan yang tersedia serta lebih memperhatikan protokol kesehatan.

\section{DAFTAR PUSTAKA}

A Nasution, A Maulana, D Kurniawan. (2019). BERSAMA MEMAJUKAN DESA. Abdi Dosen: Jurnal Pengabdian Pada Masyarakat 3 (2), 99-104

Asri Masitha Arsyati, Vindi Krisna Chandra, 2020. Assement Kesiapan Kader Posyandu dalam Pelatihan Penggunaan Media Online. HEARTY Jurnal Kesehatan Masyarakat Vol.8 No.1, 2020 Agustus-February, hlm. 27-32 ISSN. 2338-7475 E-ISSN. 26207869

Azura, Dinda. (2016). Determinan Pemnfaatan Pelayanan Kesehatan Oeh Peserta Jaminan Kesehatan Nasional (JKN) Dipuskesmas Desa Binjai Kota Medan Tahun 2016. Skripsi. Medan. Sumatera Utara.

Azwar, A. (2010). Pengantar Agetdministrasi Kesehatan. Jakarta: Bina Rupa Aksara.

Basith, Ziana Aubi. (2019). Faktor-Faktoryang Berhubungan Dengan Pemanfaatan Pelayanan Kesehatan Dipuskesmas Gayamsari Kota Semarang. Skripsi. Kota Semarang

Center For Indonesia's Strategic Development initiatives. (2020). Fact Sheet Survei Kebutuhan Puskesmas.

Chotimah, I., Oktaviani, S., \& Madjid, A. (2018). Evaluasi Program Tb Paru Di Puskesmas Belong Kota Bogor Tahun 2018. PROMOTOR, 1(2), 87-95.

Chotimah, I., Anggraini, D. (2018). Pemberdayaan Masyarakat Melalui Peningkatan Kualitas Pendidikan, Ekonomi, Kesehatan Dan Lingkungan. ABDIDOS 2 (1), 62-72. 
Chotimah, I. (2017). Gambaran Perilaku Merokok Mahasiswa Universitas Ibn Khaldun Bogor 2013. HEARTY 5 (1).

Dwimawati, E., Yanuaringsih, G.P., Pangaribuan, R., ...Gurning, F.P., Pratama, M.Y. (2021). Smoke exposure at home to the incidence of pneumonia in children under 5 years old. Indian Journal of Forensic Medicine and Toxicologythis link is disabled, 2021, 15(1), pp. 1872-1878

Dwimawati, E., \& Anisa, N. (2018). Faktor-faktor yang berhubungan dengan pengetahuan kesehatan reproduksi remaja di SMK YAK 1 bogor kecamatan tanah sareal kota Bogor provinsi Jawa Barat tahun 2018. PROMOTOR, 1(2), 80-86.

D.N. Afiyani, E. Dwimawati, S. Pujiati. (2020). Gambaran Status Gizi Berdasarkan Antropometri Pada Mahasiswa Fakultas Ilmu Kesehatan Masyarakat Universitas Ibn Khaldun Bogor. PROMOTOR 3 (1), 50-55.

E. Dwimawati, F. Beliansyah, S.A. Zulfa. (2019). Pemberdayaan Masyarakat Melalui Pemanfaatan Teknologi Dalam Rangka Meningkatkan Kualitas Sumber Daya Manusia Di Desa Gunung Menyan. Abdi Dosen: Jurnal Pengabdian Pada Masyarakat 3 (1). Keputusan Menteri Kesehatan Republik Indonesia. (2007). 377/Menkes/SK/III/2007 Tentang Standar Profesi Perekam Medis dan Informasi Kesehatan. Jakarta

Fatimah, Siti Dan Fitri Indrawati. (2020). Faktor Pemanfaatan Pelayanan Kesehatan di Puskesmas. Higeiajournal Of Public Health Research And Development. Kota Semarang

F Azka, TN Prastia, FD Pertiwi. (2020). GAMBARAN PENGETAHUAN IBU TENTANG TEKNIK MENYUSUI DI KELURAHAN TEGALGUNDIL KOTA BOGOR. PROMOTOR 3 (3), 241-250

FD Pertiwi, SN Nurdiana. (2019). HUBUNGAN SIKAP DENGAN PENGALAMAN (BULLYING) PADA SISWA SMKN 2 KOTA BOGOR. HEARTY: Jurnal Kesehatan Masyarakat 7 (1)

Fitrianingtyas, Pertiwi, dan Rachmania, W. Faktor-Faktor yang Berhubungan dengan Kejadian Kurang Energi Kronis (KEK) pada Ibu Hamil di Puskesmas Warung Jambu Kota Bogor. HEARTY Jurnal Kesehatan Masyarakat. 2018;6(2):1-8.

Hastono, Sutanto Priyo. (2016). Analisis Data Pada Bidang Kesehatan. Jakarta. Rajawali Pers.

Hidana, Rachma, Robby Shaputra, dan Husnah Maryati. (2018). Faktor-Faktor Yang Berhubungan Denganpemanfaatan Pelayanan Kesehatanoleh Pasien Luar Wilayahdi Puskesmas Tanah Sareal Kota Bogor Tahun 2018. Promotor Jurnal Mahasiswa Kesehatan Masyarakat. Vol.1 No.2. 2018.

Irawan, Bambang, dan Asmaripa Ainy. 2018. Analisis Faktor-Faktor Yang Berhubungan Dengan Pemanfaatan Pelayanan Kesehatan Pada Peserta Jaminan Kesehatan Nasional Di Wilayah Kerja Puskesmas Payakabung Kabupaten Ogan Ilir. Jurnal Ilmu Kesehatan Masyarakat, 9(3):189-197.

Jones, S.G. (2012). Develepment Of Mukti-Dimentional Healthy Care Access Index. ESRI Health Journal. 3(2):75-86. 
Kementerian Kesehatan Republik Indonesia. (2019). Data Dasar Puskesmas kondidi 31 Desember 2018

Kementerian Kesehatan Republik Indonesia. (2020). Petunjuk Teknis Pelayanan Puskesmas Pada masa Pandemi COVID-19

Kementrian Kesehatan Republik Indonesia. (2020). Data dan informasi profil kesehatan Indonesia 2019. Jakarta.

Kepala Tata Usaha Puskesmas Parung. (2020). Data dan informasi Puskesmas Parung.

Kotler. (2003). Marketing Manajement (11th ed). New Jersey: Pearson Education.

Lavesque, J., Mark, F. H., Grant, R. (2013). Patient-Centred Access To Health Care Conceptualissing Access At The Interface of Health Systems And Populations. Internasional Journal For Equaliy In Health.

Manal, Naomi. (2018). Determinan Pemanfaatan Pelayanan Kesehatan Oleh Peserta Penerima Bantuan Iuran (PBI) Di Puskesmas Desa Lalang Kecamatan Medan Sunggal. Skripsi. Medan. Sumatera Utara.

Mubarak, W.I., dan Cahyatin, N (2009). Ilmu Kesehatan Masyarakat Teori dan Aplikasi. Jakarta: Salemba Medika

Muhazam, F. (2014). Memperkenalkan Sosiologi Kesehatan. Jakarta: Penerbit Univrsitas Indonesia (UI-Press).

Munawar. (2020). "Faktor Yang Berhubungan Dengan Pemanfaatan Pelayanan Kesehatan Di Puskesmas Barrang Lompo Kota Makassar Tahun 2017". Skripsi. Kota Makassar.

Notoadmodjo, S. (2007). Kesehatan Masyarakat Ilmu dan Seni. Jakarta; Rineka Cipta.

Notoatmodjo, S (2011). Kesehatan Masyarakat Ilmu Dan Seni. Jakarta: Rineka Cipta.

Notoatmodjo, S. (2010). Motodelogi Penelitian Kesehatan. Jakarta: Rineka Cipta.

Notoatmodjo, S. (2014). Ilmu Perilaku Kesehatan. Jakarta: Rineka Cipta.

N. Oktaviani, I. Avianty, and E. D. Mawati, "Faktor-Faktor Yang Berhubungan Dengan Perilaku Merokok Pada Mahasiswa Pria Di Universitas Pakuan Bogor Provinsi Jawa Barat Tahun 2018," Promotor, vol. 2, no. 1, p. 44, 2019, doi: 10.32832/pro.v2i1.1788.

Novitasari, Y., Mawati, E. D., \& Rachmania, W. (2019). Faktor-Faktor Yang Berhubungan Dengan Perilaku Pemberian Asi Ekslusif Di Puskesmas Tegal Gundil Kota Bogor Jawa Barat Tahun 2018. PROMOTOR Jurnal Mahasiswa Kesehatan Masyarakat, 2(4), 324-333. https://doi.org/http://dx.doi.org/10.32832/pro.v2i4.2246.

Pejabat Pengelola Informasi Dan dokumentasi Pemerintah Kota Bogor. (2020). Peta Sebaran COVID-19 Kabupaten Bogor.

Peraturan Menteri Kesehatan Republik Indonesia. Nomor 43. Tahun (2019). Pusat Kesehatan Masyarakat

Peraturan Menteri Kesehatan Republik Indonesia.Nomor 75. Tahun (2014). Pusat kesehatan masyarakat

Profil Kesehatan Kabupaten Bogor. (2015). BAB VI Sumber Daya Kesehatan.

Puti, W. C. (2013). HubunganKualitas Pelayanandan Kepuasan terhadap Loyalitas Pasien Rawat jalan dan Rawat InapRumah Sakit Otorita Batam. Skripsi. Bandung: Universitas Widyatama. 
Putri, Alifia Fernanda. 2019. Pentingnya Orang Dewasa Awal Menyelesaikan Tugas Perkembangannya. SCHOULID: Indonesian Journalof School Counseling (2019), 3(2), 35-40.

Pertiwi, F. D., Hariansyah, M., \& Prasetya, E. P. (2019). FAKTOR RISIKO STUNTING PADA BALITA DIKELURAHAN MULYAHARJA TAHUN 2019. PROMOTOR, 2(5). https://doi.org/10.32832/pro.v2i5.2531

S Nurdiana, FD Pertiwi, E Dwimawati. (2021). FAKTOR-FAKTOR YANG BERHUBUNGAN DENGAN PENGALAMAN BULLYING DI SMK NEGERI 2 BOGOR PROVINSI JAWA BARAT TAHUN 2018. PROMOTOR 3 (6), 605-613

Sari MM, Nurkamila N, Mawati ED. Faktor-Faktor yang Mempengaruhi Kepatuhan Ibu Hamil dalam Melakukan Pemeriksaan Kehamilan di Puskesmas Cibungbulang Kabupaten Bogor Provinsi Jawa Barat Tahun 2018. Jurnal Mahasiswa Kesehatan Masyarakat [Internet]. 2018;1(2):96-103. Available from: http://ejournal.uikabogor.ac.id/index.php/PROMOTOR/article/view/1595

Siyoto, S., \& Muhith, A. (2015). Persepsi Pemanfaatan Pelayanan Kesehatan di Puskesmas oleh Keluarga Penerima JAMKESMAS. Jurnal Medica Majapahit,7(1).

Sugiyono. (2015). Metode Penelitian Kuantitatif, Kualitatif, dan R\&B. Bandung: Alfabeta.

Tampubolon, Apriyanti. (2018). Determinn Pemanfaatan Pelayanan Kesehatan Oleh Peserta Mandiri Jaminan Kesehatan Nasional (JKN) Di Puskesmas Parlilitan Tahun 2018. Skripsi. Sumatera Utara.

Wahyuni, Nanik Sri. (2012). Faktor-Faktor Yang Berhubungan Dengan Pemanfaatan Pelayanan Kesehatan Di Puskesmas Sumber Rejo Kota Balikpapan Provinsi Kalimantan Timur Tahun 2012. Skripsi. Depok. 